\title{
GAMBARAN PENGETAHUAN REMAJA TENTANG KESEHATAN REPRODUKSI DI SMPN HALIWEN, NUSA TENGGARA TIMUR
}

\author{
Oleh \\ Maria Anna Motu' \\ Djulianus Tes Mau' \\ Elfrida Dana R. Rohi ${ }^{3)}$ \\ 1) 2) 3) Program Studi Keperawatan Universitas Timor, Kampus Atambua, Jl. Wehor - \\ Kabuna , Haliwen, Nusa Tenggara Timur. 85711
}

\begin{abstract}
ABSTRAK
Masa remaja adalah masa berproses mencari identitas diri mendaapatkan pengakuan dari masyarakat. Mereka berusaha semaksimal mungkin agar menjadi bagian dari masyarakat. Penelitian ini bertujuan untuk mengetahui pengetahuan remaja tentang kesehatan reproduksi Di SMPN Haliwen. Desain penelitian yang digunakan adalah pendekatan kuantitatif dengan metode deskriptif murni. Sampel dalam penelitian ini adalah siswa - siswi SMPN Haliwen yang memenuhi kriteria inklusi sebanyak 123 orang. Alat pengumpul data adalah instrumen berupa kuesioner. Diketahui dari 123 responden 54 responden $(43,9 \%)$ memiliki pengetahuan baik, 51 responden $(41,5 \%)$ memiliki pengetahuan cukup dan 18 responden $(14,6 \%)$ memiliki pengetahuan kurang. Disimpulkan bahwa pengetahuan remaja tentang kesehatan reproduksi Di SMPN Haliwen sudah masuk dalam kategori baik. Oleh karena itu diharapkan agar siswa - siswi dapat menjalankan peran dan fungsi reproduksi dengan baik.
\end{abstract}

Kata kunci : Pengetahuan, kesehatan reproduksi, remaja.

\section{DESCRIPTION OF ADOLESCENT KNOWLEDGE ABOUT REPRODUCTIVE HEALTH AT SMPN HALIWEN, EAST NUSA TENGGARA}

\author{
OLEH \\ Maria Anna Motu' \\ Djulianus Tes $\mathrm{Mau}^{2}$ \\ Elfrida Dana R. Rohi ${ }^{3)}$ \\ 1) 2) 3) Study Program Nurse Universitas Timor, Kampus Atambua, Jl. Wehor - Kabuna , \\ Haliwen, Nusa Tenggara Timur. 85711
}

\begin{abstract}
Adolescence is a process of seeking self - identity to gain recognition from their community as much as possible in order to become part of the community. This study aims to determine the knowledge of adolescents about reproductive health in SMPN Haliwen. Research design using quantitative approach with pure descriptive method. The sample in this study were students of SMPN Haliwen who meet the inclusion criteria as many as 123 samples. Known from 123 respondents $(43,9 \%)$ have good knowledge, 51 respondents $(41,5 \%)$ have enough knowledge, and 18 respondents $(14,6 \%)$ have less knowledge. It was concluded that adolescent knowledge about reproductive health in the good category. Therefore it is expected that students can perform the role and function of reproduction weel.
\end{abstract}

Keywords : Knowledge, adolescent, reproductive health. 


\section{Latar Belakang}

Masa remaja adalah suatu fase perkembangan yang dinamis dalam kehidupan seorang individu. Masa ini merupakan periode transisi dari masa ke masa dewasa yang di tandai dengan kecepatan pertumbuhan dan perkembangan fisik, mental, emosional serta sosial. Masa remaja di mulai antara usia 11 atau 12 tahun sampai dengan 20 tahun, yaitu menjelang masa muda, saat di mana remaja menjadi siswasiswi dalam sebuah institusi pendidikan (Seoetjinigsih, 2007). Pendidikan sangat di butuhkan dalam perkembangan siswa- siswi sebagai remaja. Perkembangan yang sangat pesat pada siswa baik mental maupun fisik membutuhkan pengetahuan tentang psikologi dan biologi agar kebutuhannnya dapat tercapai dengan optimal. Pengetahuan adalah hasil dari tahu dan ini terjadi setelah orang melakukan penginderaan terhadap suatu objek tertentu (Notoadmojo, 2007). Kesehatan reproduksi di artikan sebagai suatu kondisi sehat yang bukan saja bebas dan penyakit atau kecacatan, namun sehat baik secara mental maupun sosial yang berkaitan dengan sistem, fungsi, dan proses reproduksinya (MakhfudliEfendi, 2013). Memasuki masa remaja yang di awali dengan terjadinya kematangan seksual, maka remaja akan dihadapkan pada keadaan yang memerlukan penyesuaian untuk dapat menerima perubahan - perubahan yang terjadi. Kematangan seksual, dan terjadinya perubahan bentuk tubuh sangat berpengaruh pada kehidupan kejiwaan remaja. Suatu keadaan sejahtera, fisik, mental dan sosial secara utuh, tidak semata - mata bebas dari penyakit atau kecacatan dalam semua hal yang berkaitan dengan sistem reproduksi serta fungsi dan prosenya (Widyastuti, $2009: 1)$.

Jumlah remaja di dunia lebih dari satu miliar dengan $85 \%$ diantaranya berada di negara berkembang yaitu sekitar 1 dan 6 manusia di bumi adalah remaja (Irawan,2016). Berdasarkan senus penduduk tahun 2010, jumlah pendidikan indonesia sebanyak 237.6 juta jiwa, 63.4 juta diantaranya adalah remaja yang tersedia dari pria sebanyak 32.164 .436 jiwa (5.70\%) 
dan perempuan sebanyak

belum memahami pentingnya 31.279.012 jiwa (49.30\%) yaitu kesehatan reproduksi.

Kesehatan reproduksi pada sekitar $27 \%$ dari total populasi (Irawan, 2016). Berdasarkan data badan statistik Jawa Tengah tahun 2015 jumlah penduduk menurut kelompok 10 - 14 tahun dengan total 2.792.672 jiwa, jenis kelamin perempuan sebanyak 1.368 .808 jiwa dan 1.431.864 jiwa laki - laki. Kelompok umur $15-19$ tahun berjumlah 2.836.471 jiwa dengan jenis klamin perempuan sebanyak 1.378.658 jiwa dan laki - laki 1.457.813 jiwa (Ismail dkk,2015) . Diseluruh dunia pada tahun 2013 ada 35 juta orang hidup dengan HIV yang meliputi 16 juta perempuan dan 3,2 juta anak berusia <15 tahun. Jumlah infeksi baru pada tahun 2013 sebesar 2,3 juta yang terdiri dari 1,9 juta dewasa dan 240.000 anak usia < 15 tahun. Berdasarkan studi pendahuluan Dinas Pendidikan Kabupaten Belu data menunjukkan siswa- siswi SMP rata - rata di Kabupaten Belu 10280 siswa, dengan usia 12 - 15 tahun, sedangkan di SMPN Haliwen jumlah siswa - siswi secara keseluruhan 510 siswa rata - rata berusia 12 - 14tahun, yang sebagian 
akses terhadap informasi dan pelayanan kesehatan (Djama, 2017).

Peningkatan pengetahuan remaja mengenai kesehatan reproduksi harus di tunjang dengan materi komunikasi, informasi dan edukasi (KIE) yang tegas tentang penyebab dan konsekuensi perilaku seksual, apa yang harus di lakukan dan di lengkapi dengan informasi megenai sarana pelayanan yang bersedia menolong seandainya telah terjadi kehamilan yang tidak di inginkan atau tertular ISR/PMS. Hingga saat ini, informasi tentang kesehatan reproduksi disebarluaskan dengan pesan - pesan yang sama dan tidak fokus, terutama bila mengarah pada perilaku seksual (Djama, 2017). Jumlah fasilitas kesehatan reproduksi yang menyeluruh untuk remaja sangat terbatas. Walaupun ada, pemanfaatannya relatif terbatas pada remaja dengan masalah kehamilan atau persalinan tidak direncanakan. Keperihatinan akan jaminan kerahasiaan (Privacy) atau kemampuan membayar, dan kenyataan atau pesepsi remaja terhadap sikap senang yang ditunjukkan oleh pihak petugas kesehatan, semakin membatasi akses pelayanan lebih jauh, meski pelayanan itu ada. Disamping itu, terdapat pula layanan legal yang berkaitan dengan pemberiaan pelayanan dan informasi kepada kelompok remaja (Djama,2017). Berdasarkan fenomena diatas maka penulis tertarik untuk melakukan penelitian tentang Gambaran tingkat pengetahuan remaja tentang kesehatan reproduksi. Tujuan dari penelitian ini adalah untuk mengetahui gambaran tingkat pengetahuan remaja tentang kesehatan reproduksi Di SMPN Haliwen.

\section{METODE PENELITIAN}

Desain penelitian dalam penelitian ini adalah kuantitatif deskriptif dengan pendekatan cros sectional yang digunakan untuk mengidentifikasi tingkat pengetahuan remaja tentang kesehatan reproduksi di SMPN Haliwen. Jumlah sampel dalam penelitian ini adalah 123 orang responden yang dipilih dengan nonprobability sampling dengan menggunakan teknik purposive sampling yaitu suatu teknik penetapan sampel dengan cara 
memilih sampel diantara populasi sesuai dengan yang dikehendaki peneliti, sehingga sampel tersebut dapat mewakili karakteristik populasi yang telah dikenal sebelumnya. Kriteria inklusinya adalah: 1) bersedia menjadi responden, 2) tidak mengalami gangguan jiwa, dan 3) siswa-siswi kelas VIII SMPN Haliwen.

Berkaitan dengan etik penelitian, sebelum menyebar kuisioner kepada responden peneliti terlebih dahulu menjelaskan tujuan dan manfaat penelitian kepada responden dan bagi siswa-siswi yang bersedia menjadi responden membubuhi tandatangan pada informed concen. Selanjutnya kerahasiaan identitas responden tetap dijaga dengan cara responden hanya memberikan nama inisial. Peneliti juga menyadari bahwa penelitian ini tidak menimbulkan efek cedera fisik maupun psikis pada responden. Peneliti juga telah mendapatkan persetujuan ijin penelitian dari Prodi Keperawatan Unimor, Kepala Kesatuan Bangsa dan Politik
Kabupaten Belu serta Kepala Sekolah SMPN Haliwen. Peneliti melakukan pengumpulan data dengan cara menyebar kuisioner kepada responden.

Alat pengumpulan data dalam penelitian ini adalah kuesinor yang diadap dari Calie Putri (2017) tentang gambaran tingkat pengetahuan remaja tentang kesehatan reproduksi dengan tingkatan validitasdan veliabitas yang dilakukan oleh penelitan terdahulu. Hasil perhitungan dengan Alpha Cronbach dinyatakan variabel jika $a>0.60$, dan hasil perhitungan didapatkan $a<0.926$, karena nilai $a$ $>0.60$, maka dinyatakan instrumen valid untuk digunakan.

Analisa data yang digunakan dalam penelitian ini adalah dengan menggunakan analisa univariat yaitu untuk mengetahui distribusi frekuensi dan prosentase dari tiap karakteristik yang ditemukan. Hasil penelitian ditampilkan dalam bentuk tabel dan diinterpretasikan secara deskriptif.

\section{HASIL PENELITIAN}


Tabel 1

Distribusi Responden Menurut usia Siswa - Siswi SMPN Haliwen Februari 2018 (n: 123)

\begin{tabular}{ccc}
\hline Variabel & frekuensi $(\mathbf{F})$ & Presentase $(\boldsymbol{\%})$ \\
\hline Usia & & 2,4 \\
\hline $16 \mathrm{Thn}$ & 3 & 17,1 \\
\hline $15 \mathrm{Thn}$ & 21 & 42,3 \\
\hline $14 \mathrm{Thn}$ & 52 & 28,5 \\
\hline $13 \mathrm{Thn}$ & 35 & 9,8 \\
\hline $12 \mathrm{Thn}$ & 12 & 100 \\
\hline Total & 123 & \\
\hline
\end{tabular}

Tabel 1 menunjukkan usia terbanyak 16 tahun sebanyak 3 orang $(2,4 \%)$, usia 15 tahunsebanyak 21 orang $(17,1 \%)$, usia 14 tahunsebanyak 52 orang $(42,3 \%)$, usia 13 tahunsebanyak 35 orang $(28,5)$ sedangkanusia 12 tahunsebanyak 12 orang $(9,8 \%)$.

Tabel 2

Disrtibusi Frekuensi Responden Menurut Jenis Kelamin Siswa - Siswi SMPN Haliwen, Februari 2018 (n: 123)

\begin{tabular}{lcc} 
JenisKelamin & Frekuensi (F) & $\begin{array}{c}\text { Presentase } \\
(\boldsymbol{\%})\end{array}$ \\
\hline Laki - laki & 61 & 49,6 \\
\hline Perempuan & 62 & 50,4 \\
\hline Total & 123 & 100 \\
\hline
\end{tabular}

Tabel 2 menunjukkan bahwa dari 123 responden laki - laki sebanyak 61 orang $(49,6 \%)$, perempuan sebanyak 51 orang $(50,4 \%)$.

Tabel 3

Distribusi Responden Berdasarkan Tingkat Pengetahuan Siswa - Siswi SMPN Haliwen, Februari 2018 (n: 123)

\begin{tabular}{rlcc}
\hline Variabel & Kategori & Frekunensi (f) & $\begin{array}{c}\text { Presentase } \\
(\%)\end{array}$ \\
\hline Pengetahuan & Baik & 54 & 43,9
\end{tabular}




\begin{tabular}{cccc} 
& Cukup & 51 & 41,5 \\
& Kurang & 18 & 14,6 \\
\hline Total & & & \\
& & 123 & 100 \\
\hline
\end{tabular}

Tabel 3 ditemukan bahwa dari 123 responden, diperoleh tingkat pengetahuan baik sebanyak 54 orang $(43,9 \%)$, tingkat pengetahuan cukup sebanyak 51 orang $(41,5 \%)$, memiliki tingkat pengetahuan kurang sebanyak 18 orang $(15 \%)$.

\section{Pembahasan}

\section{Distribusi Responden Menurut Usia}

Hasil analisis menunjukkan usia terbanyak 16 tahun sebanyak 3 orang $(2,4 \%)$, usia 15 tahun sebanyak 21 orang $(17,1 \%)$, usia 14 tahun sebanyak 52 orang $(42,3 \%)$, usia 13 tahun sebanyak 35 orang $(28,5)$ sedangkan usia 12 tahun sebanyak 12 orang $(9,8 \%)$. Data ini didukung dengan pendapat (Soetjiningsih, 2007:45) Masa remaja merupakan masa peralihan antara masa kanak kanak dan masa dewasa, yang di mulai pada saat terjadinya kematangan seksual yaitu antara usia 11 atau 12 tahun sampai dengan 20 tahun, yaitu menjelang masa dewasa muda. Selain itu menurut (Makhfudli, 2013) Remaja merupakan tahapan seseorang dimana fase anak dan dewasa yang di tandai dengan perubahan fisik, perilaku, kognitif, biologis dan emosi. Kemudian menurut (Widyastuti, 2009). Pada usia remaja sekitar 13 - 15 tahun tampak dan mencari identitas diri, ada keinginan untuk berkenan atau ketertarikan pada lawan jenis, timbul perasaan cinta yang mendalam, kemampuan berpikir abstrak (berkhayal) makin berkembang, dan berkhayal mengenai hal - hal yang berkaitan dengan seksual (Widyastuti, 2009). Sedangkan (Mubarok, 2007) berpendapat bahwa Dengan semakin 
cukup umur, tingkat kematangan seseorang akan lebih matang dalam berpikir dan bekerja.

Menurut peneliti hal ini dikarenakan bahwa banyak siswa siswi yang mulai bersekolah di usia yang lebih tua dibandingkan teman teman kelasnya, ataupun sempat tinggal kelas di jenjang sebelumnya.

\section{Distribusi Responden Menurut Jenis Kelamin}

Hasil analisi menunjukkan bahwa dari 123 responden laki - laki sebanyak 61 orang $(49,6 \%)$, perempuan sebanyak 51 orang $(50,4 \%)$. Data ini didukung dengan pendapat (Widyastuti, 2009) Pada masa remaja itu, terjadilah suatu pertumbuhan fisik yang cepat disertai banyak perubahan, termasuk didalamnya pertumbuhan organ organ reproduksi (organ seksual) sehingga tercapai kematangan yang ditunjukkan dengan kemampuan melaksanakan fungsi reproduksi, Perubahan yang terjadi pada pada pertumbuhan tersebut diikuti munculnya tanda - tanda seks primer dan seks sekunder.

Menurut peneliti hal ini dikarenakan bahwa pada perempuan dan laki - laki dimana akan mengalami perubahan pada struktur tubuh yang berbeda - beda.

\section{Distribusi Responden Berdasarkan}

\section{Tingkat Pengetahuan}

Berdasarkan dari hasil penelitian tingkat pengetahuan remaja tentang kesehatan reproduksi yang memiliki tingkat pengetahan baik sebanyak 54 orang $(43,9 \%)$, dan yang memiliki tingkat pengetahuan dengan kategori cukup sebanyak 51 orang $(41,5 \%)$, sedangkan yang memiliki tingkat pengetahuan dengan kategori kurang sebanyak 18 orang $(14,6 \%)$. Menurut peneliti sebelumnya yang dilakukan oleh Nur Ai"ni (2015) sebagian besar berpengetahuan baik dengan presentase $\quad 84,9 \%$. Menurut Widyastuti (2009) perkembangan fisik kejiwaan dan kematangan seksual remaja pembekalan pengetahuan tentang perubahan yang terjadi secara fisik, kejiwaan dan kematangan seksual akan memudahkan remaja untuk memahami serta mengatasi berbagai keadaan yang membingungkan. Menurut (Widyastuti, 2009) Kesehatan reproduksi didefinisikan 
sebagai suatu keadaan sejahtera fisik, mental dan sosial secara utuh, tidak semata - mata bebas dari penyakit atau kecacatan dalam semua hal yang berkaitan dengan sistem reproduksi, serta fungsi dan prosesnya. Menurut Mubarok (2007) ada beberapa faktor yang dapat mempengaruhi pengetahuan yaitu : umur, pendidikan, lingkungan, pekerjaan, sosial ekonomi, informasi yang diperoleh dan pengalaman.

Menurut Arikunto (2006) membuat kategori tingkat pengetahuan seseorang menjadi tiga tingkatan yang di dasarkan pada nilai persentase yaitu pengetahuan baik jika nilainya $76-100 \%$, pengetahuan cukup nilainya 56 $75 \%$ dan pengetahuan kurang nilainya $<56 \%$. Dikarenakan responden sudah banyak mendapat informasi tentang kesehatan reproduksi dari berbagai sumber, seperti pembelajaran di sekolah, penyuluhan - penyuluhan, pergaulan dengan teman sebaya, serta lewat media elektronik seperti televise dan internet. Informasi yang didapat tersebut diolah dan di pahami dengan baik karena dianggap sebagai informasi penting yang berkaitan erat dengan masa depan mereka,Hal ini mungkin disebabkan karena informasi yang didapat oleh remaja siswa - siswi tersebut tentang kesehatan reproduksi tidak begitu diperhatikan dengan baik sehinggai informasi tersebut dapat diabaikan dan hal ini disebabkan mungkin karena pengetahuan tentang kesehatan reproduksi yang masih rendah, kurang mengakses pada informasi yang benar tentang kesehatan reproduksi, dan masih malu untuk memperbincangkannya sehingga tidak ada kesadaran atau kemauan dari remaja untuk mencaritahu informasi tentang kesehatan reproduksi. Menurut Yuniarti dan Utama (2013) bahwa Salah satu isu penting yang dihadapi remaja sehubungan dimulainya kematangan seksual dan berfungsinya alat reproduksi adalah risiko terjadinya hubungan seksual menyimpang dan tidak aman, karena remaja tidak tahu tentang kesehatan reproduksi dari sumber yang benar dancara yang tepat. Untuk itu remaja perlu mendapat informasi pengetahuan tentang kesehatan reproduksi, agar memiliki pemahaman yang benar dalam 
menjalani masa -masa sulit dalam kehidupannya yang penuh gejolak. Selain itu hasil penelitian menurut Yuniarti dan Utama (2013) menunjukkan bahwa tingkat pengetahuan kesehatan reproduksi pada siswa SMA Bantul lebih baik disebabkan karena mereka selain memperoleh pengetahuan dari guru, mereka juga memperoleh informasi kesehatan reproduksi melalui media elektronik atau media cetak, misalnya televisi, internet atau majalah, sedangkan sebagian kecil yang mempunyai pengetahuan rendah mungkin disebabkan karena kurang menyerap informasi tentang materi kesehatan reproduksi dan kurangnya keinginan serta motivasi untuk mencari informasi - informasi mengenai kesehatan.

Menurut peneliti bahwa ketika siswa - siswi SMP tidak mendapatkan penjelasan tentang kesehatan reproduksi maka akan berdampak pada kurangnya pengetahuan.

\section{Kesimpulan}

Dari hasil penelitian yang dilakukan peneliti pada tanggal 23 februari 2018 di SMPN Haliwen tentang "Gambaran Tingkat Pengetahuan Remaja Tentang Kesehatan Reproduksi”. Peneliti mengambil kesimpulan sebagai berikut : Responden yang diteliti sebanyak 123 orang dengan jenis kelamin laki - laki sebanyak 61 orang $(49,6 \%)$, dan perempuan sebanyak 62 orang $(50,4 \%)$. Rata rata responden dengan usia termuda 12 tahun dan tertua 16 tahun. Tingkat pengetahuan yang di miliki oleh remaja siswa - siswi SMPN Haliwen yaitu tingkat pengetahuan dengan kategori baik sebanyak 54 orang dengan persentase $43,9 \%$, tingkat pengetahuan cukup sebanyak 51 orang dengan persentase $41,5 \%$, dan tingkat pengetahuan dengan kategori kurang sebanyak 18 orang dengan persentase $14,6 \%$. Disarankan untuk peneliti selanjutnya dapat menggunakan hasil temuan ini untuk meneliti lebih lanjut tentang beberapa hal berikut ini: 1) dampak yang terjadi apabila remaja tidak dibekali pengetahuan tentang kesehatan reproduksi, dan 2) Menganalisis faktor - faktor yang menyebabkan rendahnya tingkat pengetahuan remaja tentang kesehatan reproduksi. 


\section{DAFTAR PUSTAKA}

BKKBN Propinsi NTT Kupang. 2008. Kesehatan Reproduksi.

BKKBN. (2015). Survei demografi dan kesehatan Indonesia. Jakarta : kementerian kesehatan.

Budiman dkk, (2014). Kapita selekta kuesioner pengetahuan dan sikap dalam penelitian kesehatan. Jakarta : Salemba Medika

Djama Tahir Nuzliati. (2017). Kesehatan Reproduksi Remaja, Jurnal Kesehatan. Poltekkes Kemenkes Ternate.

Irawan Erna,(2016).Gambaran Pengetahuan Remaja Tentang Kesehatan Reproduksi Di Kertajaya, Jurnal Ilmu Keperawatan Vol. IV, Universitas BSI.

Ismailn dkk, (2015).Jurnal Kesehatan Masyarakat Nasional Vol.10,No.1, Fakultas Kedokteran, Universitas Gadjah Mada, Indonesia.

Makhfudli, $\quad$ dkk. (2013). Keperawatan Kesehatan komunitas Teori dan Praktik Dalam Keperawatan. Jakarta : Salemba Medika.
Maulana, (2016). Panduan lengkap kehamilan memahami kesehatan reproduksi, cara menghadapi kehamilan, dan kiat mengasuh anak. Jogjakarta : Katahati.

Mubarak, (2007).Ilmu Keperawatan Komunitas Konsep Dan Aplikasi. Jakarta : Salemba Medika.

Nursalam. (2007). Metodologi Penelitian Ilmu Keperawatan. Jakarta: Salemba Medika.

Notoadmojo, (2007).Pendidikan Dan Perilaku Kesehatan. Jakarta : Rineka Cipta.

Suparyanto. (2015). Riset Kebidanan Metodologi dan Aplikasi Jogjakarta.

Soetjaningsih,( 2007). Tumbuh Kembang Remaja dan Permasalahannya. Jakarta : Sagung Seto.

Widyastuti Yani dkk. (2009). Kesehatan Reproduksi. Yogyakarta : Fitramaya.

Yuniarti A.F dan Utama B.I. (2013). Gambaran Pengetahuan Tentang Kesehatan Reproduksi Di SMA Bantul Yogyakarta, Jurnal Ilmu Keperawatan, Universitas Muhammadiyah. 
